\title{
Quantitative Magnetic Resonance Techniques as Surrogate Markers of Alzheimer's Disease
}

\author{
Kejal Kantarci and Clifford R. Jack, Jr. \\ Department of Radiology, Mayo Clinic, Rochester, Minnesota 55905
}

\begin{abstract}
Summary: Recent advances in understanding the molecular biology of Alzheimer's disease (AD) offer the promise of useful therapeutic intervention in the foreseeable future. Hence, improved methods for early diagnosis and noninvasive surrogates of disease severity in $\mathrm{AD}$ have become more imperative. Various quantitative magnetic resonance (MR) techniques that measure the anatomic, biochemical, microstructural, functional, and blood-flow changes are being evaluated as possible surrogate measures of disease progression. Cross-sectional and longitudinal studies indicate that MR-based volume measurements are potential surrogates of disease progression in AD, starting from the preclinical stages. The validity of MR-based
\end{abstract}

volumetry as a surrogate marker for therapeutic efficacy in $\mathrm{AD}$ remains to be tested in a positive disease-modifying drug trial. Recent development of amyloid imaging tracers for positron emission tomography has been a major breakthrough in the field of imaging markers for AD. Efforts to image plaques are also underway in MR imaging. As with indirect MR measures, these approaches of directly imaging the pathological substrate will need to undergo a validation process with longitudinal studies to prove their usefulness as surrogate markers in AD. Key Words: Alzheimer's disease, surrogate marker, magnetic resonance imaging, magnetic resonance spectroscopy, mild cognitive impairment, volumetry.
Alzheimer's disease (AD) is the most common cause of dementia. The number of individuals affected with the disease is expected to grow with the increasing life expectancy. Disease-modifying therapies that are being developed may decrease the social and economic impact of AD. Surrogate markers of disease progression are required for measuring treatment effects of the putative disease-modifying therapies in development. The ideal surrogate MR marker should be able to detect a fundamental feature of Alzheimer's neuropathology, be diagnostically sensitive and specific through validation in neuropathologically confirmed cases, and be precise with good test-retest reproducibility for monitoring the therapeutic effects on the pathology. Few biomarkers are likely to perform ideally in all three categories. The most promising candidates in neuroimaging are amyloid-labeling agents used in PET imaging. ${ }^{1,2}$ However, human validation studies with nuclear medicine amyloid-labeling agents are incomplete at this time. It is our belief that indirect measures of

Address correspondence and reprint requests to Kejal Kantarci, M.D., Department of Radiology, Mayo Clinic, 200 First Street SW, Rochester, MN 55905. E-mail: kantarci.kejal@mayo.edu; or Clifford R. Jack, Jr., M.D., Department of Radiology, Mayo Clinic, 200 First Street SW, Rochester, MN 55905. E-mail: jack.clifford@mayo.edu.
$\mathrm{AD}$ with quantitative MR techniques can be valid biomarkers as well, particularly of disease progression. This is the subject matter addressed in this review. Various quantitative MR techniques that measure the anatomic, biochemical, microstructural, functional, and blood-flow changes in $\mathrm{AD}$ are being evaluated.

Validating the utility of MR measurements as surrogate markers for AD requires several steps of hypothesis testing in a sequential manner: 1) quantitative MR techniques that are sensitive to the presumed pathologic changes in people with the clinical diagnosis of $\mathrm{AD}, 2$ ) quantitative MR techniques that are sensitive to the presumed early pathologic changes of AD in people who are at a elevated risk of progressing to $\mathrm{AD}$ in the future, 3 ) quantitative MR techniques that can predict future progression to $\mathrm{AD}$ in cognitively normal elderly and in risk groups, 4) quantitative MR techniques that reflect the pathologic stage across the entire severity spectrum, 5) serial MR measurements that correlate with clinical disease progression across the entire severity spectrum, and 6) serial MR measurements that correlate with clinical disease progression during therapeutic trials, and monitor therapeutic efficacy.

The initial steps in the validation process involve crosssectional studies. A variety of quantitative MR techniques 
have been evaluated cross-sectionally. MR-based volumetry is the most extensively studied MR technique and the only one for which all of the validation steps listed previously have been evaluated. There are only few longitudinal studies, which evaluated other MR techniques in $\mathrm{AD}$. This article will review the literature on quantitative MR techniques as potential surrogate markers in $\mathrm{AD}$, classified according to the validation steps listed above.

\section{Quantitative MR techniques sensitive to the presumed pathologic changes in people with the clinical diagnosis of AD: cross-sectional case-control studies}

Progression of the neurofibrillary pathology of $\mathrm{AD}$, which correlates with neuron loss, follows a hierarchical topographical course in the brain. It involves the medial temporal limbic cortical structures: the entorhinal cortex and hippocampus during the earliest stages, later progressing to paralimbic cortical areas, involving the neocortex at the later stages of the disease. ${ }^{3}$ This orderly anatomical progression of the neurofibrillary pathology is important in evaluating potential surrogate MR markers for early diagnosis and disease progression, specifically for methods using measurements from predetermined anatomic regions of interest. Because each MR marker measures a certain feature of $\mathrm{AD}$ pathology, the strategic choice of regions to study must be based on the progression of the target pathology and the stage of the disease being studied. It is expected that this approach would identify different MR measurements from different brain regions of interest that would be sensitive to pathological progression at different stages of disease severity.

Memory impairment is the earliest symptom of AD. In keeping with that, medial temporal lobe limbic cortical regions, which are essential for episodic memory function, are involved with the pathology of $\mathrm{AD}$ early in the disease course. ${ }^{3}$ Neuron and tissue loss correlate closely with the neurofibrillary pathology of $\mathrm{AD}$, and atrophy is the resultant macroscopic change. ${ }^{4}$ For this reason, the medial temporal lobe is an attractive target for MR-based volume measurements. Volume measurements from different medial temporal lobe structures have been extensively studied to differentiate patients with $\mathrm{AD}$ from cognitively normal elderly. ${ }^{5-14}$ Of these, the entorhinal cortex and hippocampus volumes are generally considered to be the most accurate in differentiating patients clinically diagnosed as AD from normal. The abilities of these measures to discriminate patients with $\mathrm{AD}$ from normal do not differ significantly. ${ }^{15,16}$ However, greater difficulty with MRI boundary definition of the entorhinal cortex compared with hippocampus is noted, resulting in better test-retest reproducibility of hippocampal measurements.
Proton MR spectroscopy $\left({ }^{1} \mathrm{H}\right.$ MRS) is a diagnostic imaging technique that is sensitive to the changes in the brain at the cellular level. With ${ }^{1} \mathrm{H}$ MRS, several of the major proton-containing metabolites in the brain are measured during a common data acquisition period. The metabolite $\mathrm{N}$-acetyl aspartate (NAA) is a marker for neuronal integrity. NAA decreases in a variety of neurological disorders including AD. ${ }^{17-21}$ The decrease of NAA or the $\mathrm{NAA} /$ creatine $(\mathrm{Cr})$ ratio shows a regional variation in $\mathrm{AD}^{22-24}$ In patients with mild to moderate $\mathrm{AD}, \mathrm{NAA} / \mathrm{Cr}$ levels are lower than normal in the posterior cingulate gyrus, whereas they are normal in the medial occipital lobe, including in the visual cortex. ${ }^{23}$ This regional pattern is in agreement with the distribution of the neurofibrillary pathology, and the associated neuron loss in people with mild to moderate $\mathrm{AD}$, indicating that regional NAA/Cr levels are potential surrogates for disease progression. Another metabolite that is consistently found to be abnormal in people with $\mathrm{AD}$ is myoinositol $(\mathrm{mI})$ or $\mathrm{mI} / \mathrm{Cr}$ ratio. ${ }^{23,25,26}$ The $\mathrm{mI}$ peak consists of glial metabolites that are responsible for osmoregulation. ${ }^{27,28}$ Elevated $\mathrm{mI}$ levels correlate with glial proliferation in inflammatory CNS demyelination. ${ }^{29}$ It is thought that the elevation of the $\mathrm{mI}$ peak is related to glial proliferation and astrocytic activation in $\mathrm{AD} .^{23,25,26,30}$ One other metabolite peak of interest in the ${ }^{1} \mathrm{H}$ MRS of the brain in $\mathrm{AD}$ is the choline (Cho) peak. Some studies identified elevated Cho and $\mathrm{Cho} / \mathrm{Cr}$ ratios, some reported normal levels in people with $\mathrm{AD}$ compared with normal. ${ }^{31}$ The largest amount of choline in the brain is in the choline-bound membrane phospholipids that are precursors of choline and acetylcholine synthesis. It has been postulated that the elevation of Cho peak is the consequence of membrane phosphotidylcholine catabolism to provide free choline for the chronically deficient acetylcholine production in $\mathrm{AD} .^{32,33}$

Diffusion-weighted MR imaging (DWI) is sensitive to the microscopic structural changes in the brain via measurement of diffusivity of water molecules. The apparent diffusion coefficient measurements of DWI indicate that the diffusivity of water is higher in the hippocampus and white matter regions in patients with $\mathrm{AD}$ than in cognitively normal elderly. ${ }^{34-37}$ Elevation of the apparent diffusion coefficients in the brains of people with $A D$ is attributed to the expansion of the extracellular space, owing to the loss of neuron cell bodies and dendrites in the gray matter and Wallerian degeneration in the white matter. Another MR technique that is sensitive to the mobility of water molecules is magnetization transfer (MT) MRI. The MT ratio of immobile protons to free protons in the hippocampus and in the whole brain is lower in patients with AD than in normal. ${ }^{38-40}$ DWI and MT MRI are both sensitive to the ultrastructural changes in the brains of people with $\mathrm{AD}$ and their usefulness in early diagnosis and disease progression remain to be explored with longitudinal studies.

Cerebral blood volume MR measurements using con- 
trast agents indicate a reduction in temporoparietal blood volume in patients with $\mathrm{AD} .{ }^{41-43}$ Another technique sensitive to cerebral blood flow but that does not require injection of contrast agents is arterial spin labeling (ASL). Significant blood flow reductions were identified in the temporal, parietal, frontal, and posterior cingulate cortices of patients with $\mathrm{AD}$ relative to controls. ${ }^{44} \mathrm{ASL}$ is an appealing technique for blood flow measurements because it does not require contrast injection or ionizing radiation. Studies are needed to compare the accuracy of ASL to nuclear medicine imaging modalities as surrogate markers for blood flow changes in AD.

Changes in cognitive function accompany and may even precede the MR-detectable microscopic and macroscopic structural changes related to $\mathrm{AD}$ pathology in the brain. For this reason, functional imaging methods are of interest for early diagnosis. Measurements of brain activation with functional MRI (fMRI) show that activation patterns are different in people with AD compared with cognitively normal elderly, using activation paradigms such as visual saccades, visual and motor responses, semantic processing, angle discrimination, and memory. ${ }^{45-53}$

All MR measurements discussed in this section are sensitive to a certain feature of AD pathology in people who are clinically diagnosed as AD. Autopsy studies, however, indicate that the pathology of $\mathrm{AD}$ precedes the clinical diagnosis of dementia, perhaps by decades. One way of evaluating MR markers for early $\mathrm{AD}$ pathology is by studying risk groups, which will be discussed in the next section.

\section{Quantitative MR techniques sensitive to the presumed early pathologic changes in people who are at an elevated risk of progressing to AD: cross-sectional case-control studies}

Although tangles and plaques are the pathological signatures of $\mathrm{AD}$, they are also commonly encountered in individuals who are not clinically demented. ${ }^{54,55}$ Typically this pathology manifests as clinical AD only after a certain quantitative threshold is reached. By the time the individual is diagnosed with $\mathrm{AD}$, a significant loss of synapse and neuron had already occurred. ${ }^{56}$ The most favorable stage for disease-modifying therapies in $\mathrm{AD}$ is before the irreversible damage occurs. People who possess early AD pathology but are not yet demented are of particular interest for preventive therapies and for determining surrogate markers of early pathology. One way of identifying people who possess early AD pathology is through studying risk groups. Aging is the strongest risk factor for AD. Higher-risk groups in the aging population are composed of individuals who have a greater probability of developing AD than their peers. The higher-risk groups are identified either by clinical examination or by family history and genetic testing.
Memory impairment is the earliest symptom of AD. Many elderly individuals with memory impairment, however, do not meet the clinical criteria for dementia. The syndrome of mild cognitive impairment (MCI) was defined on clinical grounds to identify those people with memory impairment who are not clinically demented. ${ }^{57}$ Recently, those individuals have been subclassified as amnestic MCI, single nonmemory domain, and multipledomain MCI. ${ }^{58}$ Only the outcome of people with amnestic MCI has been validated with longitudinal studies, revealing that people with amnestic MCI have a higher risk of developing $\mathrm{AD}$ than their cognitively normal peers, ${ }^{59}$ and that most of the people with amnestic MCI will progress to $\mathrm{AD}$ during their lifetime. ${ }^{60} \mathrm{In}$ accordance with this, autopsy studies show that most people with amnestic MCI have early AD pathology in the limbic cortical structures that are responsible for memory function. ${ }^{56,60}$ People with MCI therefore are an important clinical group for preventive trials and for evaluating surrogate MR markers for early diagnosis and monitoring disease progression at the early stages of the disease.

In line with the autopsy findings, MR-based volume measurements indicate that the hippocampus and entorhinal cortex volumes of people with mild impairment syndromes are smaller than normal. ${ }^{61-64}$ Furthermore, similar to people with $\mathrm{AD},{ }^{1} \mathrm{H}$ MRS measurements of the posterior cingulate gyri $\mathrm{mI} / \mathrm{Cr}$ ratios ${ }^{23,65}$ and DWI measurements of the hippocampal apparent diffusion coefficients $^{36}$ are higher, whereas MT MRI measurements of temporal lobe MT ratios are lower than normal ${ }^{40,66}$ in people with MCI. These MR measurements are in agreement with the clinically transitional nature of MCI, residing between normality and dementia. An important consideration in evaluating imaging markers for early $\mathrm{AD}$ is that some members of any cognitively normal control group will likely have preclinical AD pathology. The expectation from imaging markers therefore should not be complete separation of cognitively impaired individuals from normal individuals. Some degree of overlap between the clinically identified groups is expected because preclinical $\mathrm{AD}$ pathology is not uncommon in the elderly.

A recent fMRI study showed that people with $\mathrm{MCI}$ and $\mathrm{AD}$ have a similarly low medial temporal lobe activation on a memory task when compared with cognitively normal elderly. ${ }^{67}$ Memory dysfunction is the earliest symptom of $\mathrm{AD}$, and it is common to both $\mathrm{MCI}$ and $\mathrm{AD}$. Longitudinal studies are needed to test if fMRI is sensitive to the functional changes before memory impairment becomes clinically apparent, such as in cognitively normal people who are destined to develop MCI or AD.

The APOE $\epsilon 4$ allele increases the risk of developing $\mathrm{AD}$ in a dose-dependent manner and also lowers the average age of disease onset. ${ }^{68}$ Quantitative MR studies, which investigated the association between APOE geno- 


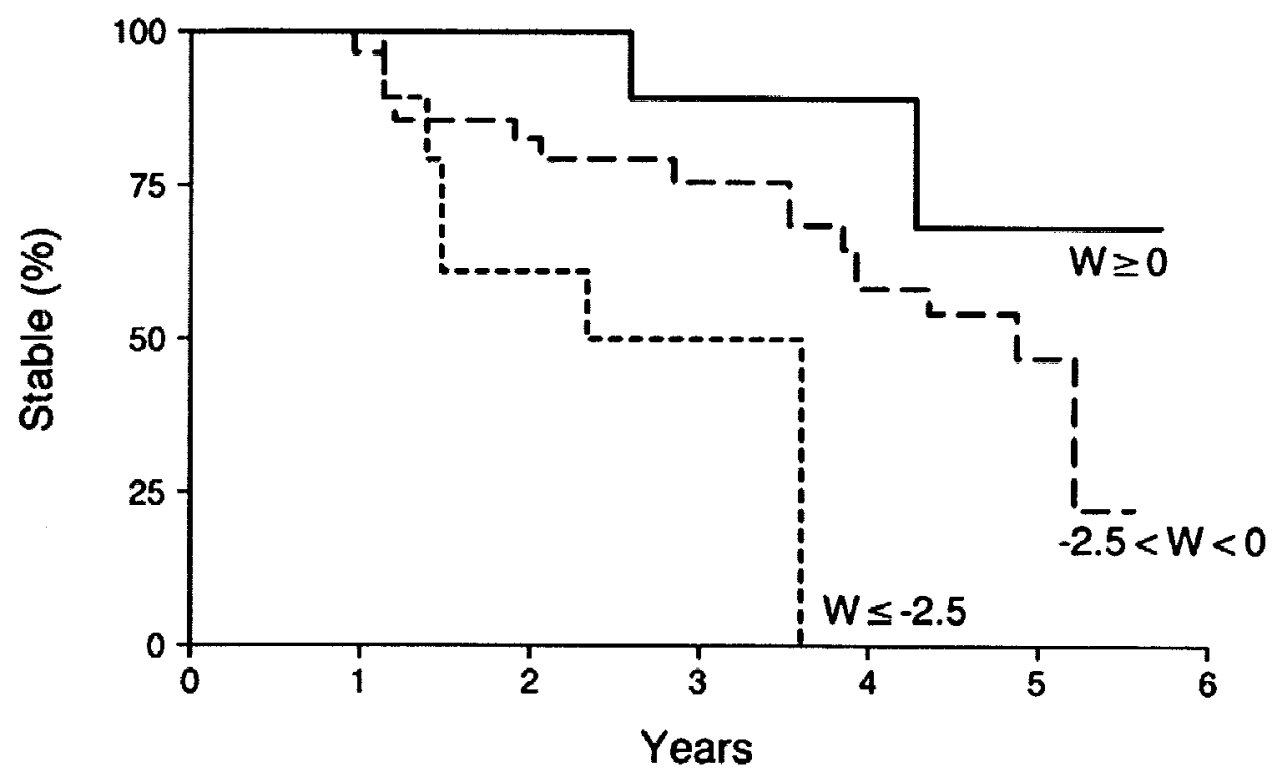

FIG. 1. Hippocampal $\mathrm{W}$ score and crossover from $\mathrm{MCI}$ to $\mathrm{AD}$. Kaplan-Meier curves of patients whose hippocampal $\mathrm{W}$ score at baseline is $\geq 0(n=13), 0>\mathrm{W}>-2.5(n=54)$, and $\leq-2.5(n=13)$. Patients with a lower hippocampal W score at baseline progress to AD faster than those with higher W scores. Reproduced with permission from Neurology 52:1397-1403, 1999.

type and MR measurements report conflicting findings. Some found smaller whole-brain and medial temporal lobe volumes in patients with AD possessing the APOE $\epsilon 4$ allele ${ }^{69,70}$ whereas others did not find any difference in the hippocampal volumes of APOE $\epsilon 4$-positive and APOE $\epsilon 4$-negative individuals. ${ }^{71-73}$ One ${ }^{1} \mathrm{H}$ MRS study showed that metabolic alterations in postmortem $\mathrm{AD}$ brain are exaggerated by APOE $\epsilon 4^{74}$; another, however, did not identify such an effect. ${ }^{75}$ The differences in age, disease duration, and the number of subjects in these studies may be responsible for the discrepancies.

\section{Quantitative MR techniques predicting future} progression to AD in cognitively normal elderly and in risk groups: longitudinal clinical cohort studies

The value of quantitative MR techniques for predicting future progression to $\mathrm{AD}$ both in cognitively normal elderly and in risk groups is assessed with longitudinal studies that test whether baseline MR measurements can predict clinical outcome in these individuals after several years of follow-up. People with mild impairment syndromes are an attractive group to study to identify quantitative MR techniques for predicting clinical outcome, because most of them eventually progress to AD. MRbased medial temporal lobe, hippocampal, and entorhinal cortex volumetry is predictive of subsequent progression to $\mathrm{AD}$ in people with mild impairment syndromes. ${ }^{76-78}$ However because patients with MCI progress to $\mathrm{AD}$ at different rates, MR-based volumetry was also tested for predicting the rate of progression to $\mathrm{AD}$ in people with MCI. Kaplan-Meier analysis performed on 80 patients with MCI who were followed at an average of 32.6 months indicates that patients with a smaller hippocam- pal volume at baseline progress to $\mathrm{AD}$ faster than the ones with larger volumes ${ }^{76}$ (FIG. 1). Furthermore, longitudinal studies on cognitively normal elderly people indicate that loss of temporal lobe volume may mark the beginning of the disease process as much as 6 years before dementia onset. ${ }^{79}$

\section{Quantitative MR techniques reflecting pathologic stage across the entire severity spectrum: MR-pathologic correlation studies}

Histopathological findings are considered to be the "gold standard" in evaluating surrogate markers for diagnosis and disease progression in $\mathrm{AD}$. Few studies have correlated quantitative MR measurements with the histopathologic diagnosis and staging so far. The correlation between antemortem MR measurements of the hippocampal volumes and postmortem Braak and Braak staging $^{3}$ indicate that hippocampal atrophy, although not specific for $\mathrm{AD}$, is a fairly sensitive marker of pathologic stage $^{80}$ and hippocampal neurofibrillary tangle burden. ${ }^{81}$ MR-based hippocampal volume measurements on postmortem samples further show a strong correlation between hippocampal volumes and neuron numbers, validating the sensitivity of the technique to hippocampal neurodegeneration. ${ }^{82}$

Neurofibrillary pathology and associated neuron loss is present in some elderly individuals with normal cognition. This pathology in normal elderly is usually confined to the medial temporal lobe corresponding to the Braak stages I and II. MR-based hippocampal volumetry on postmortem scans of the Nun Study participants suggest that hippocampal volumes may be useful in identifying early pathology of $\mathrm{AD}$ in nondemented individuals. ${ }^{83}$ 
Both antemortem and postmortem MR studies indicate that MR-based hippocampal volumetry is a valid marker for the pathologic stages of $\mathrm{AD}$, regardless of the clinical diagnosis.

\section{Serial MR measurements correlating with clinical disease progression across the entire severity spectrum: serial MRI studies in longitudinal clinical cohorts}

The neurodegenerative pathology of $\mathrm{AD}$ causes progressive atrophy and deformation of the brain over time. Serial MR measurements that are sensitive to this change can potentially be useful for tracking the pathological progression. The earliest and most severe atrophy during the progression of $\mathrm{AD}$ takes place in the medial temporal lobe. Serial MR-based volume measurements of the hippocampus in healthy young volunteers in whom no change is expected show that hippocampal volumetry is a reproducible technique with a quite low coefficient of variation $(0.28 \%) .{ }^{84}$ MR-based hippocampal measurements on serial scans of 24 patients with $\mathrm{AD}$ and 24 age-matched and gender-matched controls showed approximately 2.5 times higher rate of hippocampal volume loss in patients with $\mathrm{AD}$ compared with normal elderly. ${ }^{84}$ Another study, that followed 27 patients with $\mathrm{AD}$ and eight controls for 3 years, showed a statistically nonsignificant trend toward accelerated volume loss in the AD group compared with controls. ${ }^{85}$

As discussed in the previous section, hippocampal volume loss on MRI correlates with the pathologic progression, which begins in the medial temporal lobe years before the clinical diagnosis of AD. One study followed 30 nondemented elderly individuals annually over a mean period of 42 months. ${ }^{79}$ Twelve of these subjects cognitively declined and eventually were diagnosed as $\mathrm{AD}$ during the follow-up. Although these subjects who declined had significantly lower baseline hippocampal volumes than the ones who did not decline, the rate of hippocampal volume loss was not different between the two groups. The rate of temporal lobe volume loss, on the other hand, was higher in the decliners than in the stable ones. This result was interpreted to indicate that an individual starts showing signs of cognitive impairment only after atrophy extends beyond the hippocampus to the temporal lobe neocortex.

Another study that followed a group of normal elderly individuals, however, identified higher rates of hippocampal atrophy in normal elderly who cognitively declined and progressed to $\mathrm{MCI}$ or $\mathrm{AD}$ than the ones who were clinically stable. ${ }^{86}$ The normal elderly subjects in this study were younger than the subjects of the former study (78 vs. 86 years of age).$^{79}$ Risk for AD increases with age. An older cohort of cognitively normal elderly subjects is more likely to have a higher proportion of incipient $\mathrm{AD}$ cases that have not yet declared themselves.
In line with this argument, the hippocampal atrophy rates of the stable elderly people were higher in the older than the younger subjects $(-2.09 \%$ vs. $-1.7 \%$ per year), suggesting that undetected preclinical AD pathology in older subjects may confound estimates of atrophy rates in normally aging elderly cohorts. Furthermore, rates of hippocampal atrophy in people with MCI are higher than those in normal elderly, ${ }^{86}$ and rates of hippocampal atrophy in MCI subjects who progress to $\mathrm{AD}$ in the future are higher than MCI subjects who do not progress. People with $\mathrm{MCI}$ progress to $\mathrm{AD}$ at different rates, and although most people with MCI progress to AD during their lifetime, some do not. Baseline hippocampal volumetry in MCI provides predictive information on the risk of future progression to $\mathrm{AD}$. It is possible that measurements of the rate of hippocampal atrophy would increase the diagnostic accuracy of baseline measurements for predicting the risk and rate of progressing to $\mathrm{AD}$ in individual patients with MCI.

Another region that was studied with serial measurements is the corpus callosum. Serial measurements of the corpus callosum volumes in 21 patients with $\mathrm{AD}$ and 10 elderly controls indicate that the rate of total corpus callosum, splenium, and rostrum atrophy in patients with $\mathrm{AD}$ is higher than normal. It was thought that corpus callosum atrophy reflects loss of intracortical projecting neurons in the neocortex. If so, corpus callosum volumetry may be a potential marker for tracking neocortical pathology. Relation of the atrophic change to the pathologic involvement, however, needs to be demonstrated with postmortem studies. ${ }^{87}$

Automated or semiautomated MR volumetry techniques that are less labor-intensive than tracing specific regions of interest are being used to track the structural changes that take place within the brain during the progression of $\mathrm{AD}$. One of the most promising techniques used for this purpose is the brain boundary shift integral (BBSI) developed by Fox and Freeborough. ${ }^{88}$ The BBSI measures the change in brain boundaries first by spatially coregistering 3D scans acquired at different points in time and measuring the intensity difference over the 3D surface of the brain in the combined data. Thus the longitudinal shrinkage of the whole brain volume and the expansion of the ventricular volume can be measured. Using BBSI, brain atrophy rates on serial scans of 18 patients with $\mathrm{AD}$ were $2.37 \% \pm 1.11 \%$ per year compared with $0.41 \% \pm 0.47 \%$ per year in an age-matched and gender-matched control group. ${ }^{89}$ Furthermore, the rate of atrophy correlated with the cognitive decline in AD based on the Mini-Mental State Examination scores implying the relevance of this marker to clinical progression. ${ }^{90}$ In another study, which calculated volumes using automated techniques, the annual rate of change in the whole brain, temporal lobes, and the ventricle, identified higher rates of temporal lobe and whole brain atrophy 
TABLE 1. Summary of the Literature on Serial MR-Based Volume Measurements in AD

\begin{tabular}{|c|c|c|c|c|c|}
\hline Source & Region & $N$ (control/AD) & $\begin{array}{c}\text { Change in Controls } \\
\text { (mean } \pm \text { SD per } \\
\text { year) }\end{array}$ & $\begin{array}{c}\text { Change in AD } \\
\text { (mean } \pm \text { SD per } \\
\text { year) }\end{array}$ & $\begin{array}{l}\text { Difference } \\
\text { per year }\end{array}$ \\
\hline Kaye et al. ${ }^{79}$ & $\begin{array}{l}\text { Hippocampi } \\
\text { Parahippocampal gyri } \\
\text { Temporal lobes } \\
\text { Whole brain volume }\end{array}$ & 18/12 (preclinical AD) & $\begin{array}{r}-2.09 \% \\
-2.16 \% \\
0 \% \\
0.27 \%\end{array}$ & $\begin{array}{r}-2.33 \% \\
-2.92 \% \\
-1.27 \% \\
0.08 \%\end{array}$ & $\begin{array}{r}-0.14 \% \\
-0.76 \% \\
-1.27 \% \\
0.19 \%\end{array}$ \\
\hline Jack et al. ${ }^{84}$ & $\begin{array}{l}\text { Hippocampi } \\
\text { Temporal horns }\end{array}$ & $24 / 24$ & $\begin{array}{r}-1.55 \% \pm 1.38 \% \\
6.15 \% \pm 7.69 \%\end{array}$ & $\begin{array}{r}-3.98 \% \pm 1.92 \% \\
14.16 \% \pm 8.47 \%\end{array}$ & $\begin{array}{l}-2.43 \% \text { * } \\
8.01 \% \text { * }\end{array}$ \\
\hline Fox et al. ${ }^{89}$ & Whole brain volume & $18 / 18$ & $-0.41 \% \pm 0.47 \%$ & $-2.37 \% \pm 1.11 \%$ & $-1.96 \%$ \\
\hline Laakso et al. ${ }^{85^{\dagger}}$ & $\begin{array}{l}\text { Right hippocampus } \\
\text { Left hippocampus }\end{array}$ & $8 / 27$ & $\begin{array}{l}-1.6 \% \pm 15.1 \% \\
-3.6 \% \pm 15.1 \%\end{array}$ & $\begin{array}{l}-6.9 \% \pm 18.2 \% \\
-7.2 \% \pm 20.1 \%\end{array}$ & $\begin{array}{l}-5.3 \% \\
-3.6 \%\end{array}$ \\
\hline Teipel et al. ${ }^{87}$ & $\begin{array}{l}\text { Corpus callosum (total) } \\
\text { C1 (rostrum and genu) } \\
\text { C2 (anterior truncus) } \\
\text { C3 (middle truncus) } \\
\text { C4 (posterior truncus) } \\
\text { C5 (splenium) }\end{array}$ & $10 / 21$ & $\begin{aligned}-0.9 \% & \pm 5.0 \% \\
1.6 \% & \pm 6.3 \% \\
3.9 \% & \pm 12.1 \% \\
-1.6 \% & \pm 9.5 \% \\
-3.7 \% & \pm 12.7 \% \\
0.7 \% & \pm 3.6 \%\end{aligned}$ & $\begin{aligned}-7.7 \% & \pm 6.7 \% \\
-12.1 \% & \pm 15.1 \% \\
-10.3 \% & \pm 18.8 \% \\
-3.0 \% & \pm 10.6 \% \\
4.0 \% & \pm 18.1 \% \\
-7.3 \% & \pm 9.3 \%\end{aligned}$ & $\begin{array}{c}-6.8 \%{ }^{*} \\
-13.7 \%{ }^{*} \\
-14.2 \% \\
-1.4 \% \\
7.7 \% \\
-8 \%\end{array}$ \\
\hline Bradley et al. ${ }^{97}$ & $\begin{array}{l}\text { Brain volume } \\
\text { Ventricle volume } \\
\text { Ventricle/brain ratio }\end{array}$ & $32 / 5$ & $\begin{array}{c}-0.2 \% \pm 0.23 \% \\
4.1 \% \pm 0.9 \% \\
-4.3 \% \pm 1.1 \%\end{array}$ & $\begin{array}{c}-2.14 \% \pm 0.52 \% \\
13.0 \% \pm 2.4 \% \\
-15.6 \% \pm 2.8 \%\end{array}$ & $\begin{array}{r}-1.94 \%^{*} \\
8.9 \%^{*} \\
-11.3 \%{ }^{*}\end{array}$ \\
\hline Wang et al..$^{91}$ & $\begin{array}{l}\text { Cerebrum } \\
\text { Lateral ventricles } \\
\text { Temporal lobes }\end{array}$ & $14 / 14$ & $\begin{array}{r}-0.4 \% \pm 0.5 \% \\
1.9 \% \pm 4.2 \% \\
-0.7 \% \pm 0.5 \%\end{array}$ & $\begin{array}{r}-2.4 \% \pm 1.2 \% \\
13.8 \% \pm 4.8 \% \\
-3.4 \% \pm 2.0 \%\end{array}$ & $\begin{array}{r}-2 \%{ }^{*} \\
11.9 \%^{*} \\
-2.7 \%\end{array}$ \\
\hline Silbert et al. ${ }^{81}$ & $\begin{array}{l}\text { CNS volume } \\
\text { Ventricle volume }\end{array}$ & $24 / 15$ & $\begin{array}{r}-1.8 \mathrm{cc} \pm 9.6 \mathrm{cc} \\
3.3 \mathrm{cc} \pm 3.5 \mathrm{cc}\end{array}$ & $\begin{array}{r}-17.9 \mathrm{cc} \pm 18.0 \mathrm{cc} \\
5.5 \mathrm{cc} \pm 3.2 \mathrm{cc}\end{array}$ & $\begin{array}{r}-16.1 \mathrm{cc} \\
2.2 \mathrm{cc}\end{array}$ \\
\hline
\end{tabular}

*There is a statistically significant difference between the rate of change in controls and patients with AD.

${ }^{\dagger}$ Change in 3 years.

and ventricular enlargement in 14 people with $\mathrm{AD}$ than 14 age-matched and gender-matched controls. Combining temporal lobe atrophy rate with ventricular enlargement rate, the discriminant function completely separated normal elderly and people with AD. ${ }^{91}$ Table 1 summarizes the literature on serial MR-based volume measurements in $\mathrm{AD}$.

One drawback of global cerebral atrophy measurements is that this phenomenon is not specific to AD. A variety of neurological disorders can cause global or regional atrophy in the brain. For example cerebrovascular disease, a common disorder in the elderly, may confound the rates of cerebral atrophy in a patient with AD. Measurements of regional atrophy may be more specific to the pathological process of AD. The topology of AD pathology in the brain varies with disease progression. The rate of atrophy at specific strategic regions such as the hippocampus may be most significant during the early stages. However, as the pathology spreads to the neocortex, the rate of atrophy in other regions of the brain may be more significant than the rate of hippocampal atrophy. Because of this regional variability in the rate of atrophy, deformation of the brain is nonlinear. A fluid registration model developed by Freeborough and Fox ${ }^{92}$ uses a viscous fluid model to compute a deformation field throughout the baseline image at the voxel level, giving an estimate of volume change occurring at each voxel with serial scans over time. Statistical parametric mapping (SPM) was used to compare the deformation computed by fluid registration in 10 people with mild $\mathrm{AD}$ and 12 people with moderate $\mathrm{AD}$ and four presymptomatic cases with a family history of autosomal dominant early onset $\mathrm{AD}$ who progressed to $\mathrm{AD}$ during the follow-up. ${ }^{93}$ There was a regional variation in the rate of atrophy with increasing disease severity, which correlated with the pathologic progression of the disease. Increased rates of hippocampal and medial parietal lobe atrophy were identified in presymptomatic and mildly affected patients. Increased atrophy rates spread to the temporal and parietal lobes in people with mild to moderate AD. Atrophy rates of the frontal lobe were increased only in people with moderate AD.

Regional structural markers for disease progression may vary with the pathologic stages of AD. Measuring 


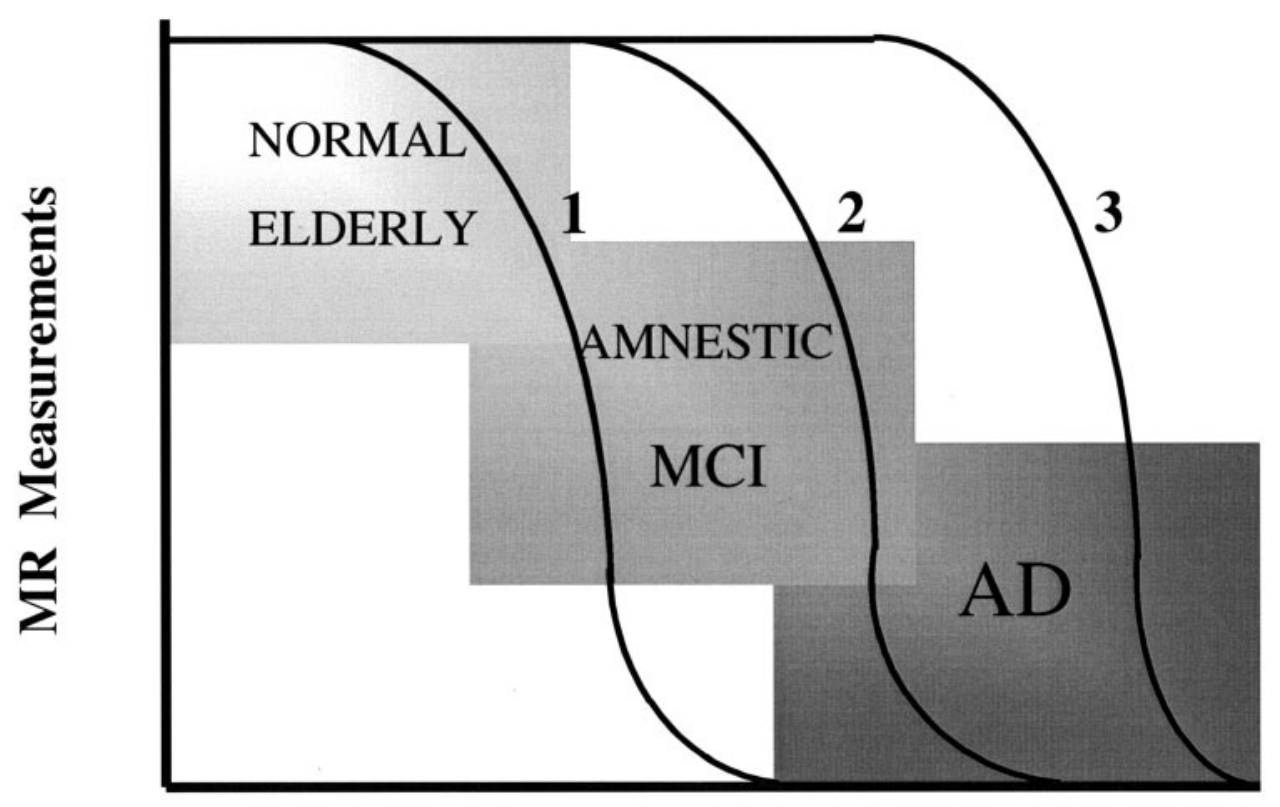

\section{Pathologic Progression}

FIG. 2. Regional structural markers for disease progression may vary with the pathologic stages of AD. This hypothetical graph represents the regional structural MR measurement change at different stages of disease progression. Regional measurements such as hippocampal atrophy rates (1) may be fastest early in the earliest pathologic stages, and may slow down later in the disease. Temporal lobe atrophy rates (2) may be fastest later during the intermediate or the $\mathrm{MCl}$ stage, and frontal lobe atrophy rates (3) may be fastest in clinically established $A D$. The choice of MR-based regional measurements should be tailored based on the severity of the disease.

global atrophy rates and statistical mapping of the difference from normal at different stages of disease severity may reveal the best regional measurement for each stage of disease progression. Longitudinally followed cognitively normal elderly and people with MCI would be of interest in such studies for understanding the earliest structural changes that may be useful as surrogate markers for therapies. Figure 2 represents a hypothetical graph of the regional structural MR measurement change at different stages of disease progression.

The only other MR technique that has been employed for serial measurements in AD is ${ }^{1} \mathrm{H}$ MRS. Three such longitudinal studies have been published so far. Although one study identified a longitudinal decrease in NAA levels in 12 people with $\mathrm{AD},{ }^{94}$ another did not reveal a change in medial temporal lobe NAA/Cr levels in 13 people with $\mathrm{AD} .{ }^{95}$ Both studies identified a correlation between cognitive decline and NAA levels. One recent study identified a significant decrease in left but not right hippocampal NAA levels in eight people with AD. ${ }^{96}$ Longitudinal ${ }^{1} \mathrm{H}$ MRS studies in larger subject groups are necessary to clarify these discrepancies.

\section{Serial MR measurements correlating with clinical} disease progression during therapeutic trials to monitor therapeutic efficacy

The standard for assessing the progression of $\mathrm{AD}$ in a living person is by clinical and neuropsychological mea- sures. Measuring the effect of a disease-modifying agent on a specific pathological process, however, requires valid markers of the pathology. MR-based volumetry is a sensitive marker for the pathologic progression of $\mathrm{AD} .^{80}$ Two studies showed that MR-based volumetry techniques in $\mathrm{AD}$ may have enough power to measure the rate of structural change in the brain in a clinical trial setting if the magnitude of treatment effect is $>10 \% .89,97$

The feasibility of MR-based volumetry as a treatment outcome measure in $\mathrm{AD}$ was tested in a multisite therapeutic trial of milameline, a centrally active muscarinic agonist. ${ }^{98}$ Using a centrally coordinated quality control program for MRI, the hippocampal volume measurements were found to be consistent across sites, validating the feasibility of multisite acquisition MR-based volumetry in AD. This study however did not prove that MR-based volumetry is a valid biomarker of therapeutic efficacy, because therapeutic efficacy was not demonstrated (the trial was not completed due to a projected lack of efficacy). The validity of MR-based volumetry as a surrogate marker for therapeutic efficacy in AD remains to be tested in a positive disease-modifying drug trial.

In another centrally acting muscarinic agonist (xanomeline) trial, brain $\mathrm{Cho} / \mathrm{Cr}$ ratios were measured with ${ }^{1} \mathrm{H}$ MRS two times within the trial period of 6 months. ${ }^{99}$ $\mathrm{Cho} / \mathrm{Cr}$ levels declined in $10 \mathrm{AD}$ patients who were 
taking xanomeline, and were stable in two AD patients who were taking a placebo. The decline in $\mathrm{Cho} / \mathrm{Cr}$ ratio was attributed to decreased free choline levels based on the hypothesis that muscarinic agonists reduce neuronal membrane breakdown by reducing the cellular requirement for free choline for acetylcholine synthesis. Although this study suggests that ${ }^{1} \mathrm{H}$ MRS may be useful in detecting therapeutic response to cholinergic agonists, long-term trials in larger groups are required to validate ${ }^{1} \mathrm{H}$ MRS as a therapeutic outcome measure in AD.

\section{Amyloid imaging and future directions}

A major recent breakthrough in the field of imaging in $\mathrm{AD}$ has been the development of amyloid imaging tracers for PET. ${ }^{1,2}$ Early efforts to image plaques are also underway in MRI. $\beta$-amyloid plaques contain significantly elevated levels of metal ions, which accelerate the $\mathrm{T} 2 *$ relaxation rate of the plaques. This property enables visualization of $\beta$-amyloid plaques as foci of decreased intensity on $\mathrm{T} 2 *$-weighted MR microscopy of postmortem brain specimens in patients with AD ${ }^{100}$ However, neither the accelerated $\mathrm{T} 2 *$ relaxation rate nor the presence of metal ions are specific to plaques. Focal areas of accelerated $\mathrm{T} 2 *$ relaxation may be present in normal individuals as well as in a variety of pathologic conditions. Furthermore, endogenous iron is contained in the hemoglobin in blood vessels and in microhemorrhages. This necessitates development of MR contrast agents that specifically bind to the $\beta$-amyloid plaques and selectively enhance these plaques on MRI. ${ }^{101,102}$ A novel approach in this regard is molecular probes that carry the MR contrast agent gadolinium-diethylenertiaminepentaacetic acid (DTPA) across the blood-brain barrier, and bind specifically to $\beta$-amyloid plaques. ${ }^{101}$ With highresolution MRI of gadolinium-DTPA-labeled $\beta$-amyloid plaques, it would be possible to noninvasively monitor the pathological progression of $\mathrm{AD}$ in vivo by directly imaging the pathology itself.

As we enter the age of imaging the amyloid pathology of $\mathrm{AD}$, new research questions arise. Although amyloid plaques are one of the key mechanisms in $\mathrm{AD}$, the social and economic impact of the disease on both the individual and society depends on the severity of clinical dementia. One important question is: how well does amyloid plaque density correlate with the clinical disease severity? Autopsy data show that synaptic loss is a better correlate of disease severity than the amyloid plaque burden. Amyloid imaging will require studies correlating clinical severity with amyloid plaque density. Another area that needs to be explored is amyloid imaging for therapy decisions. Amyloid plaques are common in cognitively normal elderly people. ${ }^{103}$ For example, will a cognitively normal person with amyloid plaques need preventive therapy, and will the change in amyloid plaque burden be a surrogate marker for clinical demen- tia progression? As with indirect MR measures, direct MR measures of the AD pathology will need to undergo a validation process with longitudinal studies to prove their usefulness as surrogate markers in AD.

Acknowledgments: This work was supported by National Institutes of Health-National Institute on Aging Grants AG11378, AG16574, and AG06786.

\section{REFERENCES}

1. Shoghi-Jadid K, Small GW, Agdeppa ED et al. Localization of neurofibrillary tangles and $\beta$-amyloid plaques in the brains of living patients with Alzheimer's disease. Am J Geriatr Psychiatry 10:24-34, 2002.

2. Bacskai BJ, Hickey GA, Skoch J et al. Four-dimensional multiphoton imaging of brain entry, amyloid binding, and clearance of an amyloid- $\beta$ ligand in transgenic mice. Proc Natl Acad Sci USA 100:12462-12467, 2003.

3. Braak H, Braak E. Neuropathological staging of Alzheimer's disease. Acta Neuropathol (Berl) 82:239-259, 1991.

4. Seab JB, Jagust WJ, Wong STS et al. Quantitive NMR measurements of hippocampal atrophy in Alzheimer's disease. Magn Reson Med 8:200-208, 1988.

5. Kesslak JP, Nalcioglu O, Cotman CW. Quantification of magnetic resonance scans for hippocampal and parahippocampal atrophy in Alzheimer's disease. Neurology 41:51-54, 1991.

6. Jack CR Jr, Petersen RC, O'Brien PC, Tangalos EG. MR based hippocampal volumetry in the diagnosis of Alzheimer's disease. Neurology 42:183-188, 1992.

7. Convit A, de Leon MJ, Golomb J et al. Hippocampal atrophy in early Alzheimer's disease: anatomic specificity and validation. Psychiatr Q 64:371-387, 1993.

8. Frisoni GB, Bianchetti A, Geroldi C, Trabucchi M. Measures of medial temporal lobe atrophy in Alzheimer's disease. J Neurol Neurosurg Psychiatry 57:1438-1439, 1994.

9. Lehericy S, Baulac M, Chiras J et al. Amygdalohippocampal MR volume measurements in the early stages of Alzheimer's disease. AJNR Am J Neuroradiol 15:927-937, 1994.

10. de Leon MJ, George AE, Golomb J et al. Frequency of hippocampal formation atrophy in normal aging and Alzheimer's disease. Neurobiol Aging 18:1-11, 1997.

11. Jack CR, Petersen RC, Xu Y et al. Medial temporal atrophy on MRI in normal aging and very mild Alzheimer's disease. Neurology 49:786-794, 1997.

12. Juottonen K, Laasko MP, Insausti R et al. Volumes of the entorhinal and perirhinal cortices in Alzheimer's disease. Neurobiol Aging 19:15-22, 1998.

13. Golebiowski M, Barcikowska M, Pfeffer A. Magnetic resonance imaging-based hippocampal volumetry in patients with dementia of the Alzheimer type. Dement Geriatr Cogn Disord 10:284-288, 1999.

14. Bobinski M, deLeon MJ, Convit A et al. MRI of entorhinal cortex in Alzheimer's Disease. The Lancet 353:38-40, 1999.

15. Juottonen K, Laakso MP, Partanen K, Soininen H. Comparative MR analysis of the entorhinal cortex and hippocampus in diagnosing Alzheimer disease. AJNR Am J Neuroradiol 20:139-144, 1999.

16. Xu Y, Jack CR Jr, O'Brien PC et al. Usefulness of MRI measures of entorhinal cortex versus hippocampus in AD. Neurology 54 1760-1767, 2000.

17. Klunk WE, Panchalingam K, Moosy J, Mc Clure RJ, Pettegrew JW. N-acetyl-L-aspartate and other amino acid metabolites in Alzheimer's disease brain: a preliminary proton nuclear magnetic resonance study. Neurology 42:1578-1585, 1992.

18. Shonk TK, Moats RA, Gifford PG et al. Probable Alzheimer's disease: Diagnosis with proton MR spectroscopy. Radiology 195: 65-72, 1995.

19. Meyerhoff DJ, MacKay S, Norman D, Van Dyke C, Fein G, Weiner MW. Axonal injury and membrane alterations in Alzhei- 
mer's disease suggested by in vivo proton magnetic resonance spectroscopic imaging. Ann Neurol 36:40-47, 1994.

20. Kwo-On-Yuen PF, Newmark RD, Budinger TF, Kaye JA, Ball MJ, Jagust WJ. Brain N-acetyl-L-aspartic acid in Alzheimer's disease: a proton magnetic resonance spectroscopy study. Brain Res 667:167-174, 1994.

21. Tsai G, Coyle JT. N-acetylaspartate in neuropsychiatric disorders. Prog Neurobiol 46:531-540, 1995.

22. Jessen F, Block W, Träber F et al. Proton MR spectroscopy detects a relative decrease of $\mathrm{N}$-acetyl aspartate in the medial temporal lobe of patients with AD. Neurology 55:684-688, 2000.

23. Kantarci K, Jack CR, Xu YC et al. Regional metabolic patterns in mild cognitive impairment and Alzheimer's disease, a ${ }^{1} \mathrm{H}$ MRS study. Neurology 55:210-217, 2000.

24. Schuff N, Capizzano AA, Du AT et al. Selective reduction of $\mathrm{N}$-acetylaspartate in medial temporal and parietal lobes in AD. Neurology 58:928-935, 2002.

25. Miller BL, Moats RA, Shonk T, Earnst T, Wooley S, Ross BD. Alzheimer disease: depiction of increased cerebral myo-inositol with proton MR spectroscopy. Radiology 187:433-437, 1993.

26. Huang W, Alexander GE, Chang L et al. Brain metabolite concentration and dementia severity in Alzheimer's disease. A ${ }^{1} \mathrm{H}$ MRS study. Neurology 57:626-632, 2001.

27. Brand A, Richter-Landsberg C, Leibfritz D. Multinuclear NMR studies on the energy metabolism of glial and neuronal cells. Dev Neurosci 15:289-298, 1993.

28. Urenjak J, Williams SR, Gadian DG et al. Proton nuclear magnetic resonance spectroscopy unambiguously identifies different neural cell types. J Neurosci 13:981-989, 1993.

29. Bitsch A, Bruhn H, Vougioukas V et al. Inflammatory CNS demyelination: histopathologic correlation with in vivo quantitative proton MR spectroscopy. AJNR Am J Neuroradiol 20:1619$1627,1999$.

30. Ernst T, Chang L, Melchor R, Mehringer M. Frontotemporal dementia and early Alzheimer disease: differentiation with frontal lobe H-1 MR spectroscopy. Radiology 203:829-836, 1997.

31. Valenzuela MJ, Sachdev PS, Wen W, Shnier R, Brodaty H, Gillies D. Dual voxel proton magnetic resonance spectroscopy in the healthy elderly: subcortical-frontal axonal $\mathrm{N}$-acetylaspartate levels are correlated with fluid cognitive abilities independent of structural brain changes. Neuroimage 12:747-756, 2000.

32. Wurtman RJ, Blusztajn JK, Marie JC. "Autocannibalism" of choline-containing membrane phospholipids in the pathogenesis of Alzheimer's disease. Neurochem Int 7:369-372, 1985.

33. MacKay S, Ezekiel F, Di Sclafani V et al. Alzheimer's disease and subcortical ischemic vascular dementia: evaluation by combining MR imaging segmentation and H-1 MR spectroscopic imaging. Radiology 198:537-545, 1996.

34. Hanyu H, Sakurai H, Takasaki M, Shindo H, Abe K. Diffusionweighted MR imaging of the hippocampus and temporal white matter in Alzheimer's disease. J Neurol Sci 156:195-200, 1998.

35. Sandson TA, Felician O, Edelman RR, Warach S. Diffusionweighted magnetic resonance imaging in Alzheimer's Disease. Dement Geriatr Cogn Disord 10:166-171, 1999.

36. Kantarci K, Jack CR, Xu YC et al. Regional diffusivity of water in mild cognitive impairment and Alzheimer's disease. Radiology 219:101-107, 2001.

37. Bozzali M, Falini A, Franceschi M et al. White matter damage in Alzheimer's disease assessed in vivo using diffusion tensor magnetic resonance imaging. J Neurol Neurosurg Psychiatry 72:742746, 2002.

38. Hanyu H, Asano T, Iwamoto T, Takasaki M, Shindo H, Abe K. Magnetization transfer measurements of the hippocampus in patients with Alzheimer's disease, vascular dementia, and other types of dementia. AJNR Am J Neuroradiol 21:1235-1242, 2000

39. Bozzali M, Franceschi M, Falini A et al. Quantification of tissue damage in $\mathrm{AD}$ using diffusion tensor and magnetization transfer MRI. Neurology 57:1135-1137, 2001.

40. van der Flier WM, van den Heuvel DMJ, Weverling-Rijnsburger AWE et al. Cognitive decline in AD and mild cognitive impairment is associated with global brain damage. Neurology 59:874879, 2002.
41. Maas LC, Harris GJ, Satlin A, English CD, Lewis RF, Renshaw PF. Regional cerebral blood volume measured by dynamic susceptibility contrast MR imaging in Alzheimer's disease: a principal components analysis. J Magn Reson Imaging 7:215-219, 1997.

42. Harris GJ, Lewis RF, Satlin A et al. Dynamic susceptibility contrast MR imaging of regional cerebral blood volume in Alzheimer disease: a promising alternative to nuclear medicine AJNR Am J Neuroradiol 19:1727-1732, 1998.

43. Bozzao A, Floris R, Baviera ME, Apruzzese A, Simonetti G. Diffusion and perfusion MR imaging in cases of Alzheimer's disease: Correlations with cortical atrophy and lesion load. AJNR Am J Neuroradiol 22:1030-1036, 2001.

44. Alsop DC, Detre JA, Grossman M. Assessment of cerebral blood flow in Alzheimer's disease by spin-labeled magnetic resonance imaging. Ann Neurol 47:93-100, 2000.

45. Thulborn K, Martin C, Voyvodic J. Functional MR imaging using a visually guided saccade paradigm for comparing activation patterns in patients with probable Alzheimer's disease and in cognitively able elderly volunteers. Am J Neuroradiol 21:524 $531,2000$.

46. Buckner R, Snyder A, Sanders A, Raichle M, Morris J. Functional brain imaging of young, nondemented, and demented older adults. $J$ Cogn Neurosci 12:24-34, 2000.

47. Johnson S, Saykin A, Baxter L et al. The relationship between fMRI activation and cerebral atrophy: comparison of normal aging and Alzheimer disease. Neuroimage 11:179-187, 2000.

48. Saykin A, Flashman L, Frutiger S et al. Neuroanatomic substrates of semantic memory impairment in Alzheimer's disease: patterns of functional MRI activation. J Int Neuropsychol Soc 5:377-392, 1999.

49. Prvulovic D, Hubl D, Sack A et al. Functional imaging of visuospatial processing in Alzheimer's disease. Neuroimage 17:14031414,2002

50. Kato T, Knopman D, Liu H. Dissociation of regional activation in mild AD during visual encoding. Neurology 57:812-816, 2001.

51. Rombouts S, Barkhof F, Veltman D et al. Functional MR imaging in Alzheimer's disease during memory encoding. AJNR Am J Neuroradiol 21:1869-1875, 2000.

52. Small S, Perera G, Delapaz R, Mayeux R, Stern Y. Differential regional dysfunction of the hippocampal formation among elderly with memory decline and Alzheimer's disease. Ann Neurol 45: 466-472, 1999

53. Sperling R, Bates J, Chua E et al. fMRI studies of associative encoding in young and elderly controls and mild Alzheimer's disease. J Neurol Neurosurg Psychiatry 74:44-50, 2003.

54. Price JL, Morris JC. Tangles and plaques in nondemented aging and preclinical Alzheimer's disease. Ann Neurol 45:358-368, 1999.

55. Schmitt FA, Davis DG, Wekstein DR, Smith CD, Ashford JW, Markesbery WR. "Preclinical" AD revisited. Neuropathology of cognitively normal older adults. Neurology 55:370-376, 2000

56. Kordower JH, Chu Y, Stebbins GT et al. Loss and atrophy of layer II entorhinal cortex neurons in elderly people with mild cognitive impairment. Ann Neurol 49:202-213, 2001.

57. Petersen RC, Smith GE, Waring SC, Ivnik RJ, Tangalos EG, Kokmen E. Mild cognitive impairment clinical characterization and outcome. Arch Neurol 56:303-308, 1999.

58. Petersen RC, Doody R, Kurz A, Mohs RC, Morris JC, Rabins PV, Ritchie K, Rossor M, Thal L, Winblad B. Current concepts in mild cognitive impairment. Arch Neurol 58:1985-1992, 2001.

59. Petersen RC, Stevens JC, Ganguli M, Tangalos EG, Cummings JL, DeKosky ST. Practice parameter: Early detection of dementia: mild cognitive impairment (an evidence-based review). Report of the Quality Standards Subcommittee of the American Academy of Neurology. Neurology 56:1133-1142, 2001.

60. Morris JC, Storandt M, Miller JP, McKeel DW, Price JL, Rubin EH, Berg L. Mild cognitive impairment represents early-stage Alzheimer disease. Arch Neurol 58:397-405, 2001.

61. Du AT, Schuff N, Amend D et al. Magnetic resonance imaging of the entorhinal cortex and hippocampus in mild cognitive impairment and Alzheimer's disease. J Neurol Neurosurg Psychiatry 71:431-432, 2001 
62. Krasuski JS, Alexander GE, Horwitz B et al. Volumes of medial temporal lobe structures in patients with Alzheimer's disease and mild cognitive impairment. Biol Psychiatry 43:60-68, 1998.

63. Dickerson BC, Goncharova I, Sullivan MP et al. MRI-derived entorhinal and hippocampal atrophy in incipient and very mild Alzheimer's disease. Neurobiol Aging 22:747-754, 2001.

64. De Santi S, de Leon MJ, Rusinek H et al. Hippocampal formation glucose metabolism and volume losses in MCI and AD. Neurobiol Aging 22:529-539, 2001.

65. Catani M, Cherubini A, Howard R. ${ }^{1} \mathrm{H}$ MR spectroscopy differentiates mild cognitive impairment from normal brain aging. NeuroReport 12:2315-2317, 2001.

66. Kabani NJ, Sled JG, Shuper A, Chertkow H. Regional magnetization transfer ratio changes in mild cognitive impairment. Magn Reson Med 47:143-148, 2002.

67. Machulda MM, Ward HA, Borowski B et al. Comparison of memory fMRI response among Normal, MCI, and Alzheimer's patients. Neurology 61:500-506, 2003.

68. Yasuda M, Mori E, Kitagaki $\mathrm{H}$ et al. Apolipoprotein E $\epsilon 4$ allele and whole brain atrophy in late-onset Alzheimer's disease. Am J Psychiatry 155:779-784, 1998.

69. Geroldi C, Pihlajamaki M, Laasko MP et al. APOE- $\epsilon 4$ is associated with less frontal and more medial temporal lobe atrophy in AD. Neurology 53:1825-1832, 1999.

70. Hashimoto M, Yasuda M, Tanimukai S et al. Apolipoprotein E $\epsilon 4$ and the pattern of regional brain atrophy in Alzheimer's disease. Neurology 57:1461-1466, 2001.

71. Jack CR, Petersen RC, Xu Y et al. Hippocampal atrophy and apolipoprotein E genotype are independently associated with Alzheimer's disease. Ann Neurol 43:303-310, 1998.

72. Reiman EM, Uecker A, Caselli RJ et al. Hippocampal volumes in cognitively normal persons at genetic risk for Alzheimer's disease. Ann Neurol 44:288-291, 1998.

73. Barber R, Gholkar A, Scheltens P et al. Apolipoprotein E $\epsilon 4$ allele, temporal lobe atrophy, and white matter lesions in late-life dementias. Arch of Neurol 56:961-965, 1999.

74. Klunk WE, Panchalingam K, McClure RJ, Stanley A, Pettegrew JW. Metabolic alterations in postmortem Alzheimer's disease brain are exaggerated by Apo-E4. Neurobiol Aging 19:511-515, 1998.

75. Kantarci K, Smith GE, Ivnik RJ et al. ${ }^{1} \mathrm{H}$ MRS, cognitive function, and apolipoprotein E genotype in normal aging, mild cognitive impairment and Alzheimer's disease. J Int Neuropsychol Soc 8:934-942, 2002.

76. Jack CR, Petersen RC, Xu Y et al. Prediction of AD with MRIbased hippocampal volume in mild cognitive impairment. $\mathrm{Neu}$ rology 52:1397-1403, 1999.

77. Visser PJ, Scheltens P, Verhey FR et al. Medial temporal lobe atrophy and memory dysfunction as predictors for dementia in subjects with mild cognitive impairment. $J$ Neurology 246:477$485,1999$.

78. Killiany RJ, Gomez-Isla T, Moss M et al. Use of structural magnetic resonance imaging to predict who will get Alzheimer's disease. Ann Neurol 47:430-439, 2000.

79. Kaye JA, Swihart T, Howieson D et al. Volume loss of the hippocampus and temporal lobe in healthy elderly persons destined to develop dementia. Neurology 48:1297-1304, 1997.

80. Jack CR Jr, Dickson DW, Parisi JE et al. Antemortem MRI findings correlate with hippocampal neuropathology in normal aging and dementia. Neurology 58:750-757, 2002.

81. Silbert LC, Quinn JF, Moore MM et al. Changes in premorbid brain volume predict Alzheimer's disease pathology. Neurology 61:487-492, 2003.

82. Bobinski M, de Leon MJ, Wegiel J et al. The histological validation of post mortem magnetic resonance imaging-determined hippocampal volume in Alzheimer's disease. Neuroscience 95: 721-725, 2000.

83. Goesche KM, Mortimer JA, Smith CD, Markesbery WR, Snowdon DA. Hippocampal volume as an index of Alzheimer neuro- pathology. Findings from the Nun Study. Neurology 58:14761482, 2002.

84. Jack CR, Petersen RC, Xu Y et al. Rate of medial temporal lobe atrophy in typical aging and Alzheimer's disease. Neurology 51: 993-999, 1998.

85. Laakso MP, Lehtovirta M, Partanen K, Riekkinen PJ, Soininen H. Hippocampus in Alzheimer's disease: a 3-year follow-up MRI study. Biol Psychiatry 47:557-561, 2000.

86. Jack CR, Petersen RC, Xu Y et al. Rates of hippocampal atrophy correlate with change in clinical status in aging and AD. Neurology 55:484-489, 2000.

87. Teipel SJ, Bayer W, Alexander GE et al. Progression of corpus callosum atrophy in Alzheimer's disease. Arch Neurol 59:243248, 2002.

88. Fox NC, Freebrough PA. Brain atrophy progression measured from registered serial MRI: validation and application to Alzheimer's disease. J Magn Reson Imaging 7:1069-1075, 1997.

89. Fox NC, Cousens S, Scahill R, Harvey RJ, Rossor MN. Using serial registered brain magnetic resonance imaging to measure disease progression in Alzheimer disease: power calculations and estimates of sample size to detect treatment effects. Arch Neurol 57:339-344, 2000.

90. Fox NC, Scahill RI, Crum WR, Rossor MN. Correlation between rates of brain atrophy and cognitive decline in AD. Neurology 52:1687-1689, 1999.

91. Wang D, Chalk JB, Rose SE et al. MR image-based measurement rates of change in volumes of brain structures. Part II: application to a study of Alzheimer's disease and normal aging. Magn Reson Imaging 20:41-48, 2002.

92. Freebrough PA, Fox NC. Modeling brain deformations in Alzheimer disease by fluid registration of serial 3D MR images. J Comput Assist Tomogr 22:838-843, 1998.

93. Scahill RI, Schott JM, Stevens JM, Rossor MN, Fox NC. Mapping the evolution of regional atrophy in Alzheimer's disease: Unbiased analysis of fluid-registered serial MRI. Proc Natl Acad Sci USA 99:4703-4707, 2002.

94. Adalsteinsson E, Sullivan EV, Kleinhans N, Spielman DM, Pfefferbaum A. Longitudinal decline of the neuronal marker N-acetyl aspartate in Alzheimer's disease. Lancet 355:1696-1697, 2000.

95. Jessen F, Block W, Träber F et al. Decrease of N-acetylaspartate correlates with cognitive decline of AD patients. Neurology 57: 930-932, 2001.

96. Dixon RM, Bradley KM, Budge MM, Styles P, Smith AD. Longitudinal quantitative proton magnetic resonance spectroscopy of the hippocampus in Alzheimer's disease. Brain 125:2332-2341, 2002.

97. Bradley KM, Bydder GM, Budge MM et al. Serial brain MRI at 3-6 month intervals as surrogate marker for Alzheimer's disease. Br J Radiology 75:506-513, 2002.

98. Jack CR Jr, Slomkowski M, Gracon S et al. MRI as a biomarker of disease progression in a therapeutic trial of milameline for AD. Neurology 60:253-260, 2003.

99. Satlin A, Bodick N, Offen WW, Renshaw PF. Brain proton magnetic resonance spectroscopy ( $\left.{ }^{1} \mathrm{H}-\mathrm{MRS}\right)$ in Alzheimer's disease: changes after treatment with xanomeline, an $\mathrm{M}_{1}$ selective cholinergic agonist. Am J Psychiatry 154:1459-1461, 1997.

100. Benveniste H, Einstein G, Kim KR, Hulette C, Johnson A. Detection of neuritic plaques in Alzheimer's disease by magnetic resonance microscopy. Proc Natl Acad Sci USA 96:14079-14084, 1999.

101. Poduslo JF, Wengenack TM, Curran GL et al. Molecular targeting of Alzheimer's amyloid plaques for contrast-enhanced magnetic resonance imaging. Neurobiol Dis 11:315-329, 2002.

102. Wadghiri YZ, Sigurdsson EM, Sadowski M et al. Detection of Alzheimer's amyloid in transgenic mice using magnetic resonance microimaging. Magn Reson Med 50:293-302, 2003.

103. Guillozet AL, Weintraub S, Mash DC, Mesulam MM. Neurofibrillary tangles, amyloid, and memory in aging and mild cognitive impairment. Arch Neurol 60:729-736, 2003. 